
.

\title{
Oxygen isotope constraints on the alteration temperatures of $\mathrm{CM}$ chondrites
}

Maximilien J. Verdier-Paoletti1,*, Yves Marrocchi ${ }^{2}$, Guillaume Avice ${ }^{2}$, Mathieu Roskosz ${ }^{1}$, Andrey Gurenko ${ }^{2} \&$ Matthieu Gounelle ${ }^{1,3}$

${ }^{1}$ IMPMC, MNHN, UPMC, UMR CNRS 7590, 61 rue Buffon, 75005 Paris, France

${ }^{2}$ CRPG, CNRS, Université de Lorraine, UMR 7358, Vandoeuvre les Nancy, F-54501, France

${ }^{3}$ Institut Universitaire de France, Maison des Universités, 103 bd. Saint-Michel, 75005 Paris,

*corresponding author: maverdier@mnhn.fr

Keywords: chondrites, aqueous alteration, oxygen isotopes, carbonates, alteration temperature, asteroids.

\section{Highlights:}

Carbonate O-isotope compositions of 9 CMs define a continuous trend crossing the TFL.

This mass independent trend matches that defined by bulk CM-COs and matrix (BMC trend).

CM water defines a trend (CMW) parallel to the bulk-matrix-carbonate trend (BMC).

The distance between $\mathrm{BMC}$ and $\mathrm{CMW}$ is directly related to $\mathrm{CM}$ alteration temperature.

Carbonates precipitated at higher temperatures than previously inferred $\left(50-300^{\circ} \mathrm{C}\right)$.

7 


\section{Abstract}

We report a systematic oxygen isotopic survey of Ca-carbonates in nine different $\mathrm{CM}$ chondrites characterized by different degrees of alteration, from the least altered known to date (Paris, 2.7-2.8) to the most altered (ALH 88045, CM1). Our data define a continuous trend that crosses the Terrestrial Fractionation Line (TFL), with a general relationship that is indistinguishable within errors from the trend defined by both matrix phyllosilicates and bulk O-isotopic compositions of CM chondrites. This bulk-matrix-carbonate (BMC) trend does not correspond to a mass-dependent fractionation (i.e., slope 0.52 ) as it would be expected during fluid circulation along a temperature gradient. It is instead a direct proxy of the degree of Oisotopic equilibration between ${ }^{17,18} \mathrm{O}$-rich fluids and ${ }^{16} \mathrm{O}$-rich anhydrous minerals. Our Oisotopic survey revealed that, for a given $\mathrm{CM}$, no carbonate is in

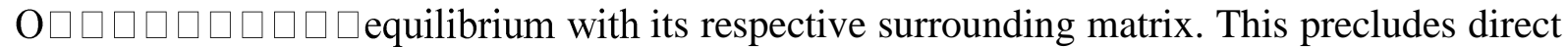
calculation of the temperature of carbonate precipitation. However, the O-isotopic compositions of alteration water in different CMs (inferred from isotopic mass-balance calculation and direct measurements) define another trend (CMW for CM Water), parallel to BMC but with a different intercept. The distance between the BMC and CMW trends is directly related to the temperature of $\mathrm{CM}$ alteration and corresponds to average carbonates and serpentine formation temperatures of $110{ }^{\circ} \mathrm{C}$ and $75{ }^{\circ} \mathrm{C}$, respectively. However, carbonate O-isotopic variations around the BMC trend indicate that they formed at various temperatures ranging between $50-300^{\circ} \mathrm{C}$, with $50 \%$ of the carbonates studied here showing precipitation temperature higher than $100^{\circ} \mathrm{C}$. The average $\Delta^{17} \mathrm{O}$ and the average carbonate precipitation temperature per chondrite are correlated, revealing that all CMs underwent similar maximum temperature peaks, but that altered CMs experienced protracted carbonate precipitation event(s) at lower temperatures than the least altered CMs. Our data suggest that the $\Delta^{17} \mathrm{O}$ 
value of $\mathrm{Ca}$-carbonates could be a reliable proxy of the degree of alteration experienced by CM chondrites.

\section{1- Introduction}

Some chemically primitive chondrites have recorded intense episodes of hydrothermal alteration that have strongly modified their petrography. This is the case of CM and CI chondrites that are made mostly of secondary minerals such as phyllosilicates, carbonates, and oxides (Brearley, 2006). Though it is widely accepted that hydrothermal alteration occurred on their respective parent-bodies (see however Ciesla, 2003), the physics, chemistry and duration of that process is still poorly understood (Brearley, 2006).

Constraining the hydrothermal alteration of water-rich bodies is important for multiple reasons. First, a large number of asteroids have been affected by hydrothermal alteration, as recorded by the ubiquitous detection of spectroscopic hydration features (Rivkin et al., 2002). Second, fluid circulation can potentially modify the nature and abundance of organics (Ehrenfreund et al., 2001; Le Guillou et al., 2012) and can change the L/D ratio of amino acids (Burton et al., 2014). Because water-rich bodies are the source of water and organics on Earth (Marty et al., 2016), hydrothermal alteration of their parent bodies must have played a key role in Earth's evolution by incorporating and deeply stabilizing water in the structure of minerals. In this study, the physicochemical conditions that prevailed during fluid circulation on water-rich parent bodies is constrained by the oxygen isotopic composition of calcium carbonates of a diversity of $\mathrm{CM}$ chondrites.

In this context, carbonates are of particular interest among secondary minerals, because they: (i) are ubiquitous in CM and CI chondrites (Johnson and Prinz, 1993; Lee et al., 2014), and (ii) directly precipitate from the alteration fluids (Alexander et al., 2015). The oxygen isotopic composition of carbonates therefore represents a valuable proxy of the 
isotopic evolution of the fluid phase during alteration. In particular, oxygen isotopic compositions are used both as a geothermometer and to track the degree of homogenization of the two dominant oxygen reservoirs present in chondrites, namely minerals and ices.

$\mathrm{CM}$ chondrites are a target of choice because they represent $25 \%$ of all carbonaceous chondrite falls and may represent the dominant type of mineral matter in the outer Solar System (Gounelle et al., 2005). Despite the fact that they form a well-identified chemical group, CM chondrites record highly variable extents of hydrothermal alteration. Some CM chondrites are almost completely hydrated and have been classified as type 1 (Zolensky et al., 1997) while others retain mineralogies similar to the most primitive (unaltered) chondrites (e.g., Hewins et al., 2014; Marrocchi et al., 2014). Based on several proxies, such as the abundance of secondary minerals or the bulk oxygen isotopic composition, two alteration indexes have been proposed for classifying CM chondrites (Browning et al., 1996; Rubin et al., 2007). In this study we analyzed chondrites spanning the entire alteration index proposed by Rubin et al. (2007). Consequently, an attempt is made to correlate the extent of alteration to the properties of the fluid as recorded by the oxygen isotopic composition of carbonates.

Oxygen isotopes are useful for constraining the timing of secondary phase precipitation. For instance, the first in situ oxygen isotope analyses of carbonates suggested the existence of two populations of calcites characterized by distinct O-isotopic compositions (Lee et al., 2013; Tyra et al., 2012; 2016). However, additional data later indicated that carbonate O-isotopic compositions form a continuous trend on either side of the terrestrial fractionation line (TFL) in a typical three-isotope plot $\left(\delta^{17} \mathrm{O}\right.$ vs. $\delta^{18} \mathrm{O}$; Horstmann et al., 2014). These observations could reflect continuous changes of the temperature of alteration and/or the composition of the fluid from which the carbonates precipitated. In any case, the alteration conditions of CM chondrites remain largely under-constrained and require more in situ data. Here, we report a systematic study of the oxygen isotopic compositions of carbonates in nine 
$\mathrm{CM}$ chondrites with degrees of alteration ranging from the least altered known to date (Paris 2.7-2.8; Bourot-Denise et al., 2010; Hewins et al., 2014; Marrocchi et al., 2014; Rubin, 2015) to the most altered (ALH 88045 CM1; Zolensky et al., 1997).

\section{2 - Material and Methods}

We studied carbonates in 6 polished thick sections (Paris, Murchison, Cold Bokkeveld, Nogoya, Murray and Jbilet Winselwan) and 3 polished thin sections (QUE93005, ALH88045 and Pollen). Samples were coated with a $20 \mathrm{~nm}$ thick carbon layer to avoid charging effects when exposed to an electron beam. Subsequent detailed observations of carbonates of the sections were performed at the Muséum National d'Histoire Naturelle of Paris using a TESCAN Vega 2LSU scanning electron microscope (SEM). Quantitative analyses of the chemical compositions of carbonates were performed using a CAMECA SXFive electron microprobe (Camparis, Paris, France) at the University of Paris VI. A $10 \mathrm{nA}$ focused beam $(\sim 4 \mu \mathrm{m})$ accelerated to $15 \mathrm{kV}$ was used for spot analyses of carbonates with $20 \mathrm{~s}$ analysis time.

In situ oxygen isotopic measurements were performed at the CRPG-CNRS Nancy using a Cameca 1280HR secondary ion mass spectrometer (SIMS) following previously described procedures (Rollion-Bard and Marin-Carbonne, 2011). We used a $\mathrm{Cs}^{+}$primary ion beam $(15 \mathrm{keV}, \sim 0.4 \mathrm{nA})$ and an electron flow parallel to the sample surface to neutralize charge excesses. ${ }^{16} \mathrm{O},{ }^{17} \mathrm{O}^{-}$and ${ }^{18} \mathrm{O}^{-}$were detected in multi-collection mode using a Faraday cup (FC) for ${ }^{16} \mathrm{O}^{-}$and two Electron Multipliers (EMs) for ${ }^{17} \mathrm{O}^{-}$and ${ }^{18} \mathrm{O}^{-}$. The EMs Dead-time correction was applied to mass ${ }^{17} \mathrm{O}^{-}$and ${ }^{18} \mathrm{O}^{-}$. Each acquisition lasted for $420 \mathrm{~s}$, consisting of $300 \mathrm{~s}$ of pre-sputtering and $120 \mathrm{~s}$ of simultaneous continuous measurement over the three collectors. To prevent the ${ }^{16} \mathrm{OH}$ interference in the ${ }^{17} \mathrm{O}^{-}$peak, the exit slit was adjusted on the central multiplier to obtain a mass resolution of $\approx 6000$ for ${ }^{17} \mathrm{O}^{-}$. As an additional safeguard 
against the ${ }^{16} \mathrm{OH}$ interference in the ${ }^{17} \mathrm{O}^{-}$peak, we used a $\mathrm{N}_{2}$ trap to reduce the pressure in the analysis chamber (i.e., $<3 \times 10^{-9}$ mbar).

Instrumental Mass Fractionation (IMF) was determined by replicate analyses of four terrestrial standards: olivine, quartz, magnetite and calcite. The O-isotopic ratios of CM calcites were normalized to that of the terrestrial calcite standard. We also considered a linear deviation of the IMF over time, which enabled us to interpolate its values at the date and time of acquisition of each measurement. Moreover, any measurement showing a column pressure significantly above to $3.10^{-9}$ mbar in the analysis chamber, or a singular count-rate of the mass ${ }^{16} \mathrm{O}^{-}$(generally correlated to an overlapping), was considered biased and therefore excluded from the results reported here.

The $2 \sigma$ errors were $0.2-1.8 \%$ for $\delta^{17} \mathrm{O}, 0.2-2.4 \%$ for $\delta^{18} \mathrm{O}$, and $0.3-1.2 \%$ for $\Delta^{17} \mathrm{O}$ (representing deviation from the TFL, defined as $\Delta^{17} \mathrm{O}=\delta^{17} \mathrm{O}-0.52 \times \delta^{18} \mathrm{O}$ ). The error on $\Delta^{17} \mathrm{O}$ was calculated by propagating the errors on $\delta^{17} \mathrm{O}$ and $\delta^{18} \mathrm{O}$, and the standard deviation of $\Delta^{17} \mathrm{O}$ values of the four terrestrial standards. After each SIMS measurement session, all analytical spots were observed via SEM in order to check if the beam overlapped the matrix or any adjacent silicate; any such measurement was rejected.

\section{3- Results}

$\mathrm{CM}$ chondrites are generally complex breccias with lithologies characterized by significant mineralogical and chemical variations (Zolensky et al., 1997; Brearley, 2006). However, at the exception of the Paris section, all the CM chondrites surveyed in this study did not present brecciations features. Although some rare occurrences of dolomite were observed among the CM chondrites surveyed in this study, the vast majority of carbonates 
observed were calcium carbonates (Fig. 1). We thus focused our isotopic survey only on calcium carbonates and performed 91 SIMS measurements in the nine different CM chondrites selected for this study. Multiple measurements (up to three) were made on grains of sufficient size allowed it. Results are reported in Table 1.

- Paris (CM 2.7-2.8; $n=14)$

Paris Ca-carbonates exhibit $\delta^{18} \mathrm{O}$ values from $26.5( \pm 0.8)$ to $38.7( \pm 0.7) \%$ and $\delta^{17} \mathrm{O}$ values from $15.5( \pm 0.6)$ to $23.1( \pm 0.6) \%$. All $\Delta^{17} \mathrm{O}$ values plot above the TFL and range from $0.9( \pm 0.3)$ to $6.1( \pm 0.4) \%$ with an average value of $3.2( \pm 1.3) \%$. No distinct populations of calcium carbonates are observed within our data, which rather defines a continuous trend.

- Murchison (CM 2.5; $n=9)$

Murchison Ca-carbonates exhibit $\delta^{18} \mathrm{O}$ values from $22.6( \pm 0.4)$ to $33.2( \pm 0.3) \%$ and $\delta^{17} \mathrm{O}$ values from $12.1( \pm 1.0)$ to $18.5( \pm 0.8) \%$ (Fig. 2a). All our measurements display positive $\Delta^{17} \mathrm{O}$ values from $0.4( \pm 0.8)$ to $3.0( \pm 0.6) \%$ with a mean value of $1.3( \pm 0.9) \%$. As in Paris, no distinct populations of Ca-carbonates emerged from our measurements.

- Murray (CM 2.4-2.5; $n=10)$

Murray Ca-carbonates exhibit $\delta^{18} \mathrm{O}$ values from $24.3( \pm 2.4)$ to $39.7( \pm 2.4) \%$ and $\delta^{17} \mathrm{O}$ from $14.2( \pm 1.8)$ to $22.6( \pm 1.7) \%$. $\Delta^{17} \mathrm{O}$ values range from $1.3( \pm 1.2)$ to $4.2( \pm 1.2) \%$ with an average value of $2.3( \pm 1.2) \%$. Ca-Carbonates of Murray present a discontinuous trend with two distinct populations characterized by average O-isotopic compositions of $\delta^{18} \mathrm{O}=37.0$ $( \pm 2.4) \%$ and $\delta^{17} \mathrm{O}=21.7( \pm 1.8) \%(\mathrm{n}=8)$ and $\delta^{18} \mathrm{O}=25.3( \pm 2.4) \%$ and $\delta^{17} \mathrm{O}=15.3( \pm 1.8)$ $\%(n=2)$. 
- Pollen (CM 2.4; $n=4)$

Pollen Ca-carbonates exhibit $\delta^{18} \mathrm{O}$ values from $35.4( \pm 0.4)$ to $37.7( \pm 0.4) \%$ and $\delta^{17} \mathrm{O}$ values from $16.6( \pm 0.7)$ to $20.0( \pm 0.8) \%$. Three of these four measurements are grouped below the TFL with $\Delta^{17} \mathrm{O}$ values ranging from $-1.8( \pm 0.6)$ to $-1.2( \pm 0.6) \%$ whereas one measurement displays a positive $\Delta^{17} \mathrm{O}$ value of $1.6( \pm 0.7) \%$.

\section{- Jbilet Winselwan (CM 2.0-2.3; $n=18$ )}

Jbilet Winselwan Ca-carbonates exhibit $\delta^{18} \mathrm{O}$ values from $27.0( \pm 0.7)$ to $38.0( \pm 0.7) \%$ and $\delta^{17} \mathrm{O}$ from $14.7( \pm 0.8)$ to $19.3( \pm 0.7) \%$. Our data defines a trend that crosses the TFL, described by $\Delta^{17} \mathrm{O}$ values that range from $-1.1( \pm 0.5)$ to $1.4( \pm 0.5) \%$ with a mean value of 0.2 $( \pm 0.7) \%$. The whole dataset is centered on a mean O-isotopic composition of $\delta^{18} \mathrm{O}=33.5$ $( \pm 0.6) \%$ and $\delta^{17} \mathrm{O}=18.0( \pm 0.4) \%$.

\section{- Cold Bokkeveld (CM 2.2; $n=10)$}

Cold Bokkeveld Ca-carbonates exhibit $\delta^{18} \mathrm{O}$ values from $20.6( \pm 1.0)$ to $28.2( \pm 1.0) \%$ and $\delta^{17} \mathrm{O}$ values from $10.6( \pm 0.7)$ to $15.7( \pm 0.8) \%$. All values plot near the TFL, with $\Delta^{17} \mathrm{O}$ values ranging from $-0.7( \pm 0.5)$ to $1.7( \pm 0.5) \%$ and an average value of $0.3( \pm 0.9) \%$. Our measurements show no evidence for distinct populations of Ca-carbonates.

- Nogoya $(C M 2.2 ; n=6)$

Nogoya Ca-carbonates exhibit $\delta^{18} \mathrm{O}$ values from $21.9( \pm 0.6)$ to $38.9( \pm 0.7) \%$ and $\delta^{17} \mathrm{O}$ values from $9.1( \pm 0.7)$ to $19.1( \pm 0.5) \%$ (Fig. 2 b). They plot on both sides of the TFL with $\Delta^{17} \mathrm{O}$ values ranging from $-2.3( \pm 0.5)$ to $0.3( \pm 0.5) \%$ (average value of $-1.1( \pm 1.0) \%$ ). Most of the measurements in Nogoya are similar to a mean O-isotopic composition characterized by $\delta^{18} \mathrm{O}=35.5( \pm 0.6) \%$ and $\delta^{17} \mathrm{O}=18.3( \pm 0.4) \%$. However, two measurements display 
196

197

198

199

200

201

202

203

204

205

206

207

208

209

210

211

212

213

214

215

216

217

218

lighter isotopic compositions with $\delta^{18} \mathrm{O}=21.9( \pm 0.6) \%$ o, $\delta^{17} \mathrm{O}=9.1( \pm 0.7) \%$ and $\delta^{18} \mathrm{O}=$ $23.5( \pm 0.6) \%, \delta^{17} \mathrm{O}=10.4( \pm 0.7) \%$.

- QUE 93005 (CM 2.1; $n=10)$

QUE 93005 Ca-carbonates exhibit $\delta^{18} \mathrm{O}$ values from $16.6( \pm 0.3)$ to $33.4( \pm 0.4) \%$ and $\delta^{17} \mathrm{O}$ values from $5.8( \pm 0.6)$ to $16.5( \pm 0.7) \%$. The $\Delta^{17} \mathrm{O}$ falls on both sides of the TFL with values ranging from $-3.4( \pm 0.6) \%$ to $0.3( \pm 0.5) \%$ (average value of $-1.8( \pm 1.3) \%$ ). The measurements are relatively scattered and show no evidence for the existence of two distinct populations of Ca-carbonates.

- $A L H 88045(C M 1 ; n=10)$

ALH 88045 Ca-carbonates exhibit $\delta^{18} \mathrm{O}$ values $16.1( \pm 0.4)$ to $29.6( \pm 0.4) \%$ and $\delta^{17} \mathrm{O}$ values from $6.6( \pm 0.6)$ to $13.8( \pm 0.6) \%$. The $\Delta^{17} \mathrm{O}$ values range from $-3.7( \pm 1.2)$ to -1.6 $( \pm 1.2) \%$ with an average value of $-2.7( \pm 0.8) \%$. Our data define a continuous trend of Oisotopic compositions.

\section{4- Discussion}

4-1 O-isotopic evolution of the alteration fluids

The oxygen isotopic compositions of Ca-carbonates determined for the nine selected CMs in this study define a trend that crosses the TFL, with a general relationship described by $\delta^{17} \mathrm{O}=0.71( \pm 0.06) \times \delta^{18} \mathrm{O}-6.5( \pm 1.9)\left(2 \sigma, \mathrm{R}^{2}=0.83, \mathrm{MSWD}=5.4\right.$, Fig. 3$)$. This continuous trend does not fall on the slope-1 line defined by chondrule anhydrous minerals in CM chondrites (Clayton \& Mayeda, 1984). In addition, it does not follow a mass-dependent fractionation trend (Fig. 3b), implying that the carbonate O-isotopic compositions were not affected by terrestrial alteration (Tyra et al., 2012) and did not result from fluid circulation 
along a temperature gradient, which would have produced a trend with a slope of 0.52 . This trend is similar, within $2 \sigma$ errors, to regressions reported by other studies (e.g., $\delta^{17} \mathrm{O}=0.65( \pm$ $0.03) \times \delta^{18} \mathrm{O}-5.4( \pm 1.2)$; Horstmann et al., 2014). However, our regression is affected by the significant deviation of the Paris carbonates from the general trend with a slight increase of their $\delta^{17} \mathrm{O}$ at high $\delta^{18} \mathrm{O}$ (Fig. 3). This deviation has been repeatedly observed for other chondrites (i.e., Maribo and LON 94091; see Horstmann et al., 2014; Lee et al., 2013) and may result from the contribution of interstellar ${ }^{17,18}$ O-enriched water to the alteration fluids from which these specific carbonates precipitated (Horstmann et al., 2014; Vacher et al., 2016). If Paris is excluded, our dataset define a linear relationship $\left[\delta^{17} \mathrm{O}=0.66( \pm 0.05) \times\right.$ $\left.\delta^{18} \mathrm{O}-4.7( \pm 1.5)\left(2 \sigma, \mathrm{R}^{2}=0.87, \mathrm{MSWD}=3.3\right)\right]$ that is indistinguishable, within $2 \sigma$ errors, from the trend defined by the bulk O-isotopic compositions of $\mathrm{CM}$ chondrites $\left[\delta^{17} \mathrm{O}=0.68( \pm\right.$ 0.02) $\times \delta^{18} \mathrm{O}-3.9( \pm 0.2)$; Fig. 3; (Clayton and Mayeda, 1999)]. Henceforth, we do not consider Paris when comparing the slope defined by our data with those reported in literature, but we include Paris to determine the temperature of carbonate precipitation. The general trend defined by Ca-carbonates has a slope of 0.66 (excluding Paris) or 0.71 (including Paris) that does not correspond to mass-dependent fractionation defined by a slope of 0.52 in a $\delta^{17} \mathrm{O}-$ $\delta^{18} \mathrm{O}$ diagram due to mass differences between oxygen isotopes. This implies that carbonate O-isotopic compositions were set during alteration by progressive equilibration of a primitive ${ }^{17,18} \mathrm{O}$-rich fluid with ${ }^{16} \mathrm{O}$-rich anhydrous minerals (Benedix et al., 2003; Clayton and Mayeda, $1999 ; 1984)$. This assertion is supported by the continuous trend observed between Cacarbonates and the bulk O-isotopic compositions of $\mathrm{CM}$ chondrites (Fig. 3, Clayton and Mayeda, 1999).

In addition to the general Ca-carbonate trend, in situ analyses reveal additional oxygen isotopic variations within the different $\mathrm{CMs}$ that can be summarized as follow (Table 1): 
(i) a low variability around an average value (e.g., Pollen), (ii) an important dispersion along a continuous trend (e.g., QUE 93005) and (iii) two distinct populations, each of them showing low O-isotopic variability (e.g., Murray). Our isotopic survey also reveals that no CM shows $\delta^{18} \mathrm{O}$ variations in $\mathrm{Ca}$-carbonates at constant $\Delta^{17} \mathrm{O}$, even those defining a continuous trend with extreme oxygen isotopic variations (e.g., QUE 93005 with $\delta^{18} \mathrm{O}$ ranging from 16.6 to $33.4 \%$; Table 1). These results support models in which Ca-carbonates could have recorded either a single continuous precipitation event or successive episodic precipitation events (Benedix et al., 2003; De Leuw et al., 2010). In such schemes, ${ }^{17,18}$ O-rich Ca-carbonates correspond to early precipitates from primitive fluids that did not suffer significant O-isotopic exchanges with ${ }^{16} \mathrm{O}$-rich anhydrous silicates (Benedix et al., 2003; Clayton and Mayeda, 1999; Lee et al., 2013; Tyra et al., 2016; 2012). Conversely, lighter isotopic compositions indicate that carbonates formed following significant alteration, and as the O-isotopic compositions of fluids converged toward the typical ${ }^{16} \mathrm{O}$-rich values of anhydrous silicates. Both bulk and in situ data (Fig. 2 \& 3) thus identify O-isotopic exchange between ${ }^{16} \mathrm{O}$-rich silicates and ${ }^{17,18} \mathrm{O}$-rich fluid as the key process that controls the O-isotopic composition of the alteration fluids from which the Ca-carbonates precipitated.

The formation temperature of Ca-carbonate in $\mathrm{CM}$ chondrites remains disputed, and proposed values have varied significantly over past decades. More generally, the sequence of 263 formation of both carbonates and other secondary phases (e.g., serpentine, tochilinite) is poorly understood. Initially, the temperature of Ca-carbonate precipitation was estimated to be in the range $0-25^{\circ} \mathrm{C}$ based on the $\mathrm{O}$-isotopic equilibrium between $\mathrm{Ca}$-carbonates and phyllosilicates in the Murchison meteorite (Clayton and Mayeda, 1984). Later measurements 
suggested instead that most $\mathrm{Ca}$-carbonates in $\mathrm{CM}$ chondrites are not in isotopic equilibrium with co-existing phyllosilicates (Benedix et al., 2003). However, a few CM chondrites (i.e., Nogoya and Murchsion; Baker et al., 2002; Benedix et al., 2003) present mass-dependent relationships between secondary phases that have been used to determine the alteration temperature. This approach led to contrasting results with alteration temperatures ranging from $0-20^{\circ} \mathrm{C}$ (Benedix et al., 2003) to $80-120^{\circ} \mathrm{C}$ (Baker et al., 2002). Finally, clumped-isotope thermometry of $\mathrm{CO}_{2}\left(\Delta^{47}\right)$ was applied to $\mathrm{CM}$ secondary phases, providing formation temperature estimates of $20-70^{\circ} \mathrm{C}$ for Ca-carbonate precipitation (Guo and Eiler, 2007).

Our data do not fall on a mass-dependent line (i.e., slope 0.52). This confirms the lack of general oxygen isotopic equilibrium between Ca-carbonates and phyllosilicates in the matrix (Fig. 2a; Clayton and Mayeda, 1999), even for Nogoya contrary to previous results (slope 0.59; Fig. 2b; Benedix et al., 2003). Therefore, our results confirm that the difference in $\delta^{18} \mathrm{O}$ between coexisting secondary phases cannot be used to estimate a hypothetical single alteration temperature of $\mathrm{CM}$ chondrites. On the other hand, considering the entire dataset, a continuous trend is observed between O-isotopic signatures of bulk $\mathrm{CO}-\mathrm{CM}$ chondrites and Ca-carbonates (Fig. $3 \& 4 a$ ), which implies that serpentines also broadly align along this trend as they represent the main component of CM chondrites (Brearley, 2006). Previous matrix measurements present $\delta^{17} \mathrm{O}-\delta^{18} \mathrm{O}$ values along this trend, plotting in-between Ca-carbonates and bulk CO-CM chondrites (Fig. 2 \& 4a; Clayton and Mayeda, 1999; 1984). Note that the data dispersion around this line will be discussed in details below (see sub-section 4.3), and may possibly be used to derive a relatively precise timing of phase precipitation.

O-isotopic compositions of CM water (hereafter CMW) have been determined either by isotopic mass balance calculations and/or direct measurements (Baker et al., 2002; Clayton and Mayeda, 1999; 1984; Guo and Eiler, 2007). Compilation of all available data defines a 
291 line $\left(\mathrm{R}^{2}=0.99\right.$; Fig. 4a) with a slope of 0.69 that is indistinguishable, within error, from the

292 bulk-matrix-carbonates trend (hereafter BMC; slope $0.66 \pm 0.05$ ), but has a different intercept

293 (i.e., -2.12 for CMW vs. -4.7 fro BMC; Fig. 4a). The meaning of this line is uncertain, but we

294 will now explore the possibility that this line was formed by equilibration between two

295 distinct reservoirs of water and silicates.

296

297

298

299

300

301

302

303

304

305

306

307

308

309

310

311

312

313

314

\section{4-3 Average alteration temperature of CM chondrites and its variability}

In the context of closed-system isotopic exchange between two distinct reservoirs, parallel trends in a three-isotope diagram, and the positions of the data points along them, can be interpreted in different ways, as summarized in Fig. 5 (Matsuhisa et al., 1979). At a constant temperature, but variable water/rock ratio or equilibration degree, the isotopic evolution of the fluid and silicate reservoirs will follow parallel lines in a $\delta^{17} \mathrm{O}-\delta^{18} \mathrm{O}$ diagram, with the distance between the lines corresponding to the equilibrium isotopic fractionation factor $\alpha$ (Fig. 5a,b). As fractionation depends on temperature, if equilibration occurs at different temperatures but at a fixed water/rock ratio and equilibrium degree, a set of parallel lines will be generated with their respective distances decreasing with increasing equilibration temperature (Fig. 5c). If formation temperature varies between samples, each couple of water and rock data will sit on their own parallel lines and the whole data set will not be seen as parallel straight lines anymore. That the BMC and the CMW trends are straight lines strongly suggests that a single temperature (or a very narrow temperature interval) was recorded by this large dataset. This also implies that we can use the distance between BMC and CMW to estimate the average formation temperatures of secondary phases, as the distance between both lines results from the mass-dependent isotopic fractionation occurring, at low temperature, between carbonates and water and between serpentine and water, respectively 
(Chacko et al., 2001; Kim and O'Neil, 1997; Matsuhisa et al., 1979). Hence, we first consider the distance between the $\mathrm{BMC}$ and $\mathrm{CMW}$ trends to obtain an average formation temperature of Ca-carbonates and serpentine. Monte Carlo simulations were then used to account for the statistical scattering of our data points around BMC. Finally, we subsequently address our individual measurements to obtain a range of formation temperatures for $\mathrm{CM} \mathrm{Ca}$-carbonates.

We assumed that a given phase $x$ (either Ca-carbonate or serpentine) located on the BMC trend (Fig. 4a) formed from a fluid plotting along the CMW line (in other words, that the formation of the secondary phases occurs at equilibrium). Although such an assumption is valid for Ca-carbonates, it represents an approximation in the case of serpentines as they do not precipitate directly from the alteration fluids and could thus present partial isotopic equilibrium. Nonetheless, in the following, we assume complete oxygen isotopic equilibrium for both Ca-carbonates and serpentines. In this case, the O-isotopic compositions of water and the forming mineral are related by a mass-dependent relationship according to:

$$
\delta^{17} O_{x}=0.52 \times \delta^{18} O_{x}+b
$$

Hence, each measurement plotting on the BMC trend (phase $x$ ) is linked via a mass-dependent relationship to a fluid composition given by the intercept with the CMW line (Fig. 4b). This O-isotopic composition represents the fluid from which phase $x$ formed, determined by:

$$
\delta^{18} O_{H_{2} O}=\frac{2.12+\delta^{17} O_{x}-0.52 \times \delta^{18} O_{x}}{0.69-0.52}
$$

with 0.69 and 2.12 being the slope and intercept of the CMW line, respectively (Fig. 4a). Because the O-isotopic fractionations between carbonates and water and between serpentine and water are temperature-dependent (Chacko et al., 2001; Kim and O'Neil, 1997), the determination of the formation temperature of carbonates and serpentine can be fit according to a linear law: 


$$
\Delta^{18} O_{c a r b-H_{2} O}=\delta^{18} O_{c a r b}-\delta^{18} O_{H_{2} O}=69.93-0.14 \times T_{c a r b}
$$

$$
\Delta^{18} O_{\text {serp }-H_{2} \mathrm{O}}=\delta^{18} O_{\text {serp }}-\delta^{18} O_{H_{2} \mathrm{O}}=52.86-0.11 \times T_{\text {serp }}
$$

with the formation temperatures $(\mathrm{K})$ of carbonate and serpentine being:

The errors on the average temperature of carbonate formation have been computed by propagation of the uncertainties on $\delta^{18} \mathrm{O}_{\text {carb }}$ following a Monte-Carlo method. In this method, random values of $\delta^{18} \mathrm{O}_{\text {carb }}$ and $\delta^{18} \mathrm{O}_{\text {water }}$ are chosen assuming a normal distribution law for the statistical behavior of these parameters. For each pair of values, a formation temperature was then computed according to Eqn. (5). This random process was repeated $10^{4}$ times. This procedure demonstrates that the formation temperatures of Ca-carbonates define normal distributions with an average formation temperature of $113 \pm 54^{\circ} \mathrm{C}$ (Fig. 6). Applying such a method to serpentine data, we determined its average formation temperature at around $75^{\circ} \mathrm{C}$ with negligible error as the uncertainties associated with the matrix O-isotopic compositions are negligible (i.e., errors are smaller than the symbols; Clayton and Mayeda, 1999).

This approach gives an average temperature of carbonate precipitation by assuming that they all fall on the trend defined by the statistic regression calculated from our isotopic data. However, this first approach is too simplistic as our in situ carbonate oxygen isotopic compositions present significant dispersions on both sides of the carbonate trend (Fig. 3). Assuming that the CMW line represents the oxygen isotopic composition of the alteration 
precipitation temperatures by connecting the O-isotopic compositions of individual $\mathrm{Ca}$ carbonates to the CMW line according to the mass-dependent isotopic fractionation between carbonate and water (Eqn. 5; see example in Fig. 5a). The underlying assumption here is that the position of the CMW line did not change significantly over the course of the alteration history of the system, which will be discussed below. Application to this method to the carbonates reported in this study provides precipitation temperatures ranging from -50 to $275^{\circ} \mathrm{C}$ with a typical error on temperature estimate of $\pm 44^{\circ} \mathrm{C}$ (Fig. 7). The important variations in temperature are not related to the errors on the O-isotopic compositions of carbonates as they define a trend with MSWD > 1 (i.e., 3.3). Note that a temperature as low as $-50^{\circ} \mathrm{C}$ appears unrealistic but the important conclusion here is that a significant fraction of the carbonates measured in this study formed at higher temperatures than previously thought. In our sampled $\mathrm{CM}$ chondrites, $75 \%$ of the carbonates analyzed formed at temperatures higher than $50^{\circ} \mathrm{C}$. Moreover, $50 \%$ precipitated at temperatures $>100^{\circ} \mathrm{C}$ (Fig. 7a). Our data also revealed a positive correlation between the average $\Delta^{17} \mathrm{O}$ and the average temperature of carbonate precipitation per chondrite (Fig. 8). Such a correlation may seem counterintuitive as it is generally proposed that CM1 chondrites were altered at higher temperatures than CM2 chondrites (Zolensky et al., 1999). Our results suggest, instead, that all CM chondrites may have experienced high temperature alteration, (at temperature higher than previously thought), and that carbonate precipitation occurred at varying temperatures in the different CMs with CM1 and CM2.1 to CM2.3 having recorded a protracted alteration during the cooling of the parent body to lower temperatures than CM2.4 and higher petrographic grades (Fig. 7b). Such a scheme is consistent with the $\Delta^{17} \mathrm{O}-\delta^{18} \mathrm{O}$ correlation (Fig. 9) showing that: (i) ${ }^{17,18} \mathrm{O}-$ rich Cacarbonates correspond to early precipitates from primitive fluids that did not yet suffer significant $\mathrm{O}$-isotopic exchanges with ${ }^{16} \mathrm{O}$-rich anhydrous silicates and (ii) altered $\mathrm{CM}$ chondrites experienced longer water-rock isotopic exchange (Fig. 4). Together, these results 
thus suggest that $\mathrm{O}$-isotopic exchange between ${ }^{17,18} \mathrm{O}$-rich fluid and ${ }^{16} \mathrm{O}$-rich anhydrous silicate took place over a long period of time but that carbonate precipitation in each $\mathrm{CM}$ occurred during punctual events in a narrow range of temperatures or, in the case of heavily altered CMs, re-equilibrated over the cooling history of the parent body.

\section{4-4 Constraints on the formation sequence of secondary phases of CM chondrites}

The precipitation sequence of secondary phases during aqueous alteration of $\mathrm{CM}$ chondrites is rather unclear. Our in situ dataset can be used to tell whether carbonates or serpentines precipitated first. To do so, we first note that the main component of $\mathrm{CM}$ chondrites is serpentine. In this respect, the relative position of the BCM and CMW lines essentially reflects the formation temperature of these hydrous silicates. Second, a single Oisotopic composition for the silicate precursor has been proposed (Clayton and Mayeda, 1984). Even if the precise composition of the putative anhydrous solids of each CM may slightly vary, it is reasonable here to assume the single value proposed by Clayton \& Mayeda (1984, 1999) as an anchor point (Fig. 4a). Within this framework, the linear regression joining the anhydrous silicate precursor, the bulk matrix, and carbonates will not necessarily be parallel to the CMW line if carbonates formed at a different temperature than the mineralogically dominant serpentine. For carbonates formed at high temperature (before serpentines), the line will intersect the CMW (Fig. S1a). This intersect will provide an estimate of the isotopic composition of the pristine heavy water reservoir (Fig. S1b). For carbonates formed or equilibrated at the same temperature (and time) as serpentines, the two lines will be parallel (Fig. S1a). Finally, for carbonates formed or equilibrated after the precipitation of serpentines, the CMW and BCM lines will diverge (Fig. S1a). 

Paris and Murchison formed before serpentines (Fig. S1b). Carbonates from Murray and Cold

Bokkeveld formed at the same time (or equilibrated at the same temperature) as serpentines

(Fig. S1c). Finally, a significant fraction of carbonates from other samples formed after the precipitation of serpentines (or equilibrated with water at lower temperatures than serpentines; Fig. S1d). Our data therefore provide a fairly precise sequence of (re)precipitation of secondary phases. Finally, it is of note that, from our data, the isotopic composition of the heavy water that equilibrated with silicates of $\mathrm{CM}$ chondrites $\left(\delta^{18} \mathrm{O}=48 \%\right.$, $\delta^{17} \mathrm{O}=31 \%$; Fig. S1b) is reasonably consistent with, yet slightly heavier than, the initial estimate proposed by (Clayton and Mayeda, 1984a): $\left(\delta^{18} \mathrm{O}=30.3 \%\right.$ o, $\delta^{17} \mathrm{O}=20.2 \%$ o. If confirmed, this would imply that the isotopic composition of carbonates from Murchison (and Paris) directly recorded the isotopic composition of the water reservoir that altered CM chondrites.

\section{4-5 Implications for the alteration conditions of CM chondrites and concluding remarks}

Our data indicate that (i) the Ca-carbonate precipitation occurred at temperature higher than previously thought and (ii) their O-isotopic compositions are a direct proxy of the degree of O-isotopic exchange between ${ }^{16} \mathrm{O}$-rich anhydrous silicates and the ${ }^{17,18} \mathrm{O}$-rich fluid. Our data also suggest that both CM1 and CM2 chondrites likely experienced high-temperature hydrothermal alteration. Such a conclusion is in line with the similar structures and chemical compositions of the insoluble organic matter (IOM) in both CM1 and CM2, which require a common temperature peak (assuming similar organic precursors) for both types of chondrites (Alexander and Cody, 2013; Kuga et al., 2015). Furthermore, our results demonstrate that most of Ca-carbonate precipitation likely predates the formation of serpentine (Fig. $6 \& 10$ ) consistent with recurring observations of Ca-carbonates pseudomorphosed by tochilinite- 
serpentine associations (Fujiya et al., 2015; Lee et al., 2013; Marrocchi et al., 2014). For the most altered CM's, a partial or total re-equilibration between carbonates and water may have occurred during cooling of the parent body below temperatures of serpentine formation, as recorded by our in situ measurements. Such low-temperature equilibration may not be kinetically favored if the silicate precursor is crystalline. For instance, there is no evidence for O-isotopic exchange between quartz and water up to at least $170^{\circ} \mathrm{C}$, regardless of grain size (Clayton et al., 1972). We note, however, that the matrix of the least altered CM, Paris, is mainly composed of amorphous silicates (Leroux et al., 2015) that, relative to crystalline silicates, could have faster O-isotopic exchange rates with water. Moreover, the occurrence of tochilinite-cronstedite intergrowths in Paris with euhedral shapes characteristic of silicates (Pignatelli et al., 2016) confirm that water-mineral interactions also occurred during the alteration of $\mathrm{CM}$ matrices. These observations strengthen the conclusion that $\mathrm{Ca}$-carbonates precipitated at high temperature from alteration fluids with varying $\mathrm{O}$-isotopic compositions. In contrast, serpentine did not precipitate directly from the fluid, but resulted from protracted interaction between water and amorphous (Le Guillou et al., 2015; Leroux et al., 2015) and/or crystalline silicates (Pignatelli et al., 2016). Hence, the lower formation temperature determined for serpentine relative to Ca-carbonates (Fig. 7) likely reflects the thermal evolution of the CM parent body during the course of alteration. In this framework, the different degrees of alteration by which CM chondrites are characterized (Fig. 4) are related to (i) different durations of fluid alteration and/or (ii) heterogeneous concentrations of water ice grains within the CM parent bodies. 
Acknowledgments

Johan Villeneuve is thanked for helpful scientific discussions. Nordine Bouden is

thanked for his assistance with isotopic measurements. This work was funded by l'Agence

Nationale de la Recherche grant ANR-14-CE33-0002-01 SAPINS (PI Yves Marrocchi). This

is SAPINS contribution \#05.

\section{References}

Alexander, C.M.O.d', Cody, G.D., 2013. Did CM and CI Chondrites get Hotter than We Think? The View from Tagish Lake. $76^{\text {Th }}$ Meteoritics and Planetary Science, abstract \#5047.

Alexander, C.M.O.d', Bowden, R., Fogel, M.L., Howard, K.T., 2015. Carbonate abundances and isotopic compositions in chondrites. Meteorit Planet Sci 50, 810-833.

Baker, L., Franchi, I.A., Wright, I.P., Pillinger, C.T., 2002. The oxygen isotopic composition of water from Tagish Lake: Its relationship to low- temperature phases and to other carbonaceous chondrites. Meteoritics \& Planetary Science 37, 977-985.

Benedix, G.K., Leshin, L.A., Farquhar, J., Jackson, T., Thiemens, M.H., 2003. Carbonates in CM2 chondrites: constraints on alteration conditions from oxygen isotopic compositions and petrographic observations. Geochim. Cosmochim. Acta 67, 1577-1588.

Bourot-Denise, M., Zanda, B., Marrocchi, Y., Greenwood, R.C., Pont, S., Hewins, R.H., Franchi, I.A., Cornen, G., 2010. Paris: The slightly altered, slightly metamorphosed CM that bridges the gap between CMs and COs., the Lunar and Planetary Science Conference 41st.

Brearley, A.J., 2006. The action of water, in: Lauretta, D.S., McSween, H.Y. (Eds.), Meteorites and Early Solar System II. Arizona University Press, pp. 587-624.

Browning, L.B., McSween, H.Y., Zolensky, M., 1996. Correlated effects in CM carbonaceous chondrites. Geochim. Cosmochim. Acta 60, 2621-2633.

Burton, A.S., Glavin, D.P., Elsila, J.E., Dworkin, J.P., Jenniskens, P., Yin, Q.-Z., 2014. The amino acid composition of the Sutter's Mill CM2 carbonaceous chondrite. Meteorit Planet Sci 49, 2074-2086.

Chacko, T., Cole, D.R., Horita, J., 2001. Equilibrium oxygen, hydrogen and carbon isotope fractionation factors applicable to geologic systems, in: Cole, J.W.V.A.R.D. (Ed.), Stable Isotope Geochemistry, Reviews of Mineralogy and Geochemistry. Mineralogical Society 
of America, Washington DC, pp. 1-81.

Ciesla, F.J., 2003. A Nebular Origin for Chondritic Fine-Grained Phyllosilicates. Science 299, 549-552.

Clayton, R.N., Mayeda, T.K., 1999. Oxygen isotope studies of carbonaceous chondrites. Geochim. Cosmochim. Acta 63, 2089-2104.

Clayton, R.N., Mayeda, T.K., 1984a. The oxygen isotope record in Murchison and other carbonaceous chondrites. Earth and Planetary Science Letters 67, 151-161.

Clayton, R.N., Mayeda, T.K., 1984b. The oxygen isotope record in Murchison and other carbonaceous chondrites. Earth and Planetary Science Letters 67, 151-161.

Clayton, R.N., O'Neil, J.R., Mayeda, T.K., 1972. Oxygen isotope exchange between quartz and water. Journal of Geophysical Research 77, 3057-3067.

De Leuw, S., Rubin, A.E., Wasson, J.T., 2010. Carbonates in CM chondrites: Complex formational histories and comparison to carbonates in CI chondrites. Meteoritics \& Planetary Science 45, 513-530.

Ehrenfreund, P., Bernstein, M.P., Dworkin, J.P., Sandford, S.A., Allamandola, L.J., 2001. The Photostability of Amino Acids in Space. ApJ 550, L95-L99.

Fujiya, W., Sugiura, N., Marrocchi, Y., Takahata, N., Hoppe, P., Shirai, K., Sano, Y., Hiyagon, H., 2015. Comprehensive study of carbon and oxygen isotopic compositions, trace element abundances, and cathodoluminescence intensities of calcite in the Murchison CM chondrite. Geochim. Cosmochim. Acta 161, 101-117.

Gounelle, M., Engrand, C., Maurette, M., Kurat, G., McKeegan, K.D., Brandstätter, F., 2005. Small Antartic micrometeorites: A mineralogical and in situ oxygen study. Meteorit Planet. Sci. 40, 917-932.

Guo, W., Eiler, J.M., 2007. Temperatures of aqueous alteration and evidence for methane generation on the parent bodies of the CM chondrites. Geochim. Cosmochim. Acta 71, 5565-5575.

Hewins, R.H., Bourot-Denise, M., Zanda, B., Leroux, H., Barrat, J.A., Humayun, M., Göpel, C., Greenwood, R.C., Franchi, I.A., Pont, S., Lorand, J.P., Cournède, C., Gattacceca, J., Rochette, P., Kuga, M., Marrocchi, Y., Marty, B., 2014. The Paris meteorite, the least altered CM chondrite so far. Geochim. Cosmochim. Acta 124, 190-222.

Horstmann, M., Vollmer, C., Barth, M.I.F., Chaussidon, M., Gurenko, A., Bischoff, A., 2014. Tracking Aqueous Alteration of CM Chondrites - Insights From In Situ Oxygen Isotope Measurements of Calcite, Lunar and Planetary Science Conference, abstract \#1761.

Johnson, C.A., Prinz, M., 1993. Carbonate compositions in CM and CI chondrites and implications for aqueous alteration. Geochim. Cosmochim. Acta 57, 2843-2852.

Kim, S.T., O'Neil, J.R., 1997. Equilibrium and nonequilibrium oxygen isotope effects in synthetic carbonates. Geochim. Cosmochim. Acta 61, 3461-3475.

Kuga, M., Marty, B., Marrocchi, Y., Tissandier, L., 2015. Synthesis of refractory organic matter in the ionized gas phase of the Solar Nebula. Proceedings of the National Academy of Sciences of the United States of America 112, 7129-7134.

Le Guillou, C., Dohmen, R., Rogalla, D., Müller, T., Vollmer, C., Becker, H.-W., 2015. New experimental approach to study aqueous alteration of amorphous silicates at low reaction rates. Chemical Geology 412, 179-192.

Le Guillou, C., Rouzaud, J.-N., Bonal, L., Quirico, E., Derenne, S., Remusat, L., 2012. High resolution TEM of chondritic carbonaceous matter: Metamorphic evolution and heterogeneity. Meteoritics \& Planetary Science 47, 345-362.

Lee, M.R., Lindgren, P., Sofe, M.R., 2014. Aragonite, breunnerite, calcite and dolomite in the $\mathrm{CM}$ carbonaceous chondrites: High fidelity recorders of progressive parent body aqueous alteration. Geochim. Cosmochim. Acta 144, 126-156.

Lee, M.R., Sofe, M.R., Lindgren, P., Starkey, N.A., Franchi, I.A., 2013. The oxygen isotope 
evolution of parent body aqueous solutions as recorded by multiple carbonate generations in the Lonewolf Nunataks 94101 CM2 carbonaceous chondrite. Geochim. Cosmochim. Acta 121, 452-466.

Leroux, H., Cuvillier, P., Zanda, B., Hewins, R.H., 2015. GEMS-like material in the matrix of the Paris meteorite and the early stages of alteration of CM chondrites. Geochim. Cosmochim. Acta 170, 1-19.

Marrocchi, Y., Gounelle, M., Blanchard, I., Caste, F., Kearsley, A.T., 2014. The Paris CM chondrite: Secondary minerals and asteroidal processing. Meteorit Planet. Sci. 49, 12321249.

Marty, B., Avice, G., Sano, Y., Altwegg, K., Balsiger, H., Hässig, M., Morbidelli, A., Mousis, O., Rubin, M., 2016. Origins of volatile elements (H, C, N, noble gases) on Earth and Mars in light of recent results from the ROSETTA cometary mission. Earth Planet. Sci. Lett. 441, 91-102.

Matsuhisa, Y., Goldsmith, J.R., Clayton, R.N., 1979. Oxygen isotopic fractionation in the system quartz-albite-anorthite-water. Geochim. Cosmochim. Acta 43, 1131-1140.

Pignatelli, I., Marrocchi, Y., Vacher, L.G., Delon, R., Gounelle, M., 2016. Multiple precursors of secondary mineralogical assemblages in CM chondrites. Meteorit Planet Sci $51,785-805$.

Rivkin, A.S., Howell, E.S., Vilas, F., Lebofsky, L.A., 2002. Hydrated minerals on asteroids: The astronomical record,, in: Bottke, W., Cellino, A., Paolicchi, P., Binzel, R.P. (Eds.), Asteroids III. Arizona University Press, pp. 235-253.

Rollion-Bard, C., Marin-Carbonne, J., 2011. Determination of SIMS matrix effects on oxygen isotopic compositions in carbonates. J. Anal. At. Spectrom. 26, 1285-5.

Rubin, A.E., 2015. An American on Paris: Extent of aqueous alteration of a CM chondrite and the petrography of its refractory and amoeboid olivine inclusions. Meteorit Planet Sci 50, $1595-1612$.

Rubin, A.E., Trigo-Rodriguez, J.M., Huber, H., Wasson, J.T., 2007. Progressive aqueous alteration of CM carbonaceous chondrites. Geochim. Cosmochim. Acta 71, 2361-2382.

Tyra, M., Brearley, A., Guan, Y., 2016. Episodic carbonate precipitation in the CM chondrite ALH 84049: An ion microprobe analysis of $\mathrm{O}$ and $\mathrm{C}$ isotopes. Geochim. Cosmochim. Acta 175, 195-207.

Tyra, M.A., Farquhar, J., Guan, Y., Leshin, L.A., 2012. An oxygen isotope dichotomy in CM2 chondritic carbonates: A SIMS approach. Geochim. Cosmochim. Acta 77, 383-395.

Vacher L.G, Marrocchi Y., Verdier-Paoletti M.J., Villeneuve J., Gounelle M., 2016. Inward radial mixing of interstellar water in the solar protoplanetary disk. The Astrophysical J. Letters 827, 1-6.

Zolensky, M.E., Bodnar, R.J., Gibson, E.K.J., Niyquist, L.E., Resse, Y., T, S.C., Wiesman, H., 1999. Asteroidal water within fluid inclusion-bearing halite in an H5 chondrite, Monahans. Science 285, 1377-1379.

Zolensky, M.E., Mittlefehldt, D.W., Lipshutz, M.E., Wang, M., Clayton, R.N., Mayeda, T.K., Grady, M.M., Pillinger, C.T., Barber, D., 1997. CM chondrites exhibit the complete petrologic range from type 2 to 1 . Geochim. Cosmochim. Acta 61, 5099-5115. 
Figure 1: Back-scattered electron micrographs of Ca-carbonates. (a) Porous Ca-carbonate surrounded by a tochilinite-cronstedtite intergrowth (TCI) rim in Jbilet Winselwan (b) Porous irregular Ca-carbonate surrounded by a TCI rim in Paris (c) Ca-carbonate cross-cut by fractures and surrounded by a microporous rim in Cold Bokkeveld (d) Ca-carbonate in Pollen surrounded by a TCI rim.

Figure 2: Oxygen isotopic compositions of Ca-carbonates in Murchison (a) and Nogoya (b),

601

602

603

604

605

606

607

Circles represent single carbonate measurements, while squares and triangles correspond to the matrix and bulk O-isotopic compositions, respectively (Clayton \& Mayeda, 1999).

Figure 3: Oxygen three-isotope plot for Ca-carbonates from the nine $\mathrm{CM}$ chondrites measured in this study (data in \%o). The light grey area corresponds to the range of bulk Oisotopic compositions determined for CM and CO chondrites (Clayton \& Mayeda, 1999), and the dark gray area corresponds to the trend defined by Ca-carbonates (excluding Paris Cacarbonates, which may reflect interstellar enrichment of alteration fluids). The terrestrial fractionation line (TFL) and the Carbonaceous Chondrite Anhydrous Mineral line (CCAM) are also represented. 
612 Figure 4: (a) Oxygen three-isotope plot showing the general bulk-matrix-carbonate (BMC) 613 trend observed between bulk CM-CO chondrites (Clayton \& Mayeda, 1999), matrix 614 phyllosilicates (Clayton et al., 1984; Clayton \& Mayeda, 1999) and Ca-carbonates (this 615 study). The CM Water line (CMW) corresponds to the trend defined by the O-isotopic 616 compositions of $\mathrm{CM}$ alteration water as determined by isotopic mass balance calculations 617 and/or direct measurements (Clayton et al., 1984; Clayton \& Mayeda, 1999; Baker et al., 618 2002, Guo and Eiler, 2007). Both trends are parallel allowing for the determination of the 619 temperature of carbonate precipitation and serpentine formation (see text). (b). Close-up 620 showing that a given carbonate located on the BMC (red point) can be connected to the Oisotopic composition of the fluid from which it precipitated (CMW line) by a mass-dependent 622 relationship. The distance between both compositions $\left(\delta^{18} \mathrm{O}_{\text {carb }}\right.$ and $\delta^{18} \mathrm{O}_{\text {water, }}$, see text $)$ is 623 directly related to temperature, allowing the temperature of carbonate precipitation to be 624 determined.

Figure 5: Theoretical considerations on the oxygen isotopic equilibration between silicates and water. (a) At a fixed temperature and water/rock ratio, the isotopic evolution of the fluid and the silicate reservoirs follow parallel lines in a $\delta^{17} \mathrm{O}-\delta^{18} \mathrm{O}$ diagram as a function of the reaction advancement. The distance between the two lines corresponds to the equilibrium

630 isotopic fractionation factor $\alpha$. $\square \square \square$ At a fixed temperature and equilibration degree, the 631 isotopic evolution of the fluid and the silicate reservoirs will follow parallel lines in a $\delta^{17} \mathrm{O}-$ $632 \delta^{18} \mathrm{O}$ diagram as a function of the water/rock ratio. (c) Equilibration at varying temperature but fixed water/rock ratio and equilibrium degree will also generate parallel lines but with 
their respective distances decreasing with increasing equilibration temperature. MDFL corresponds to the mass-dependent fractionation line (i.e., slope 0.52).

Figure 6: Density distribution of the formation temperatures of carbonates (blue) and serpentines (red) determined by the Monte-Carlo method (see text for further detail).

Figure 7: (a) Temperature of carbonate precipitation as a function of the distance between the in situ data and the CMW trend. The temperature is calculated as detailed in Fig. 5 (see text for details). The blue areas correspond to the average temperature of carbonates formation and its associated error. (b) Box plots showing median, minimum, maximum, first and last quartile of temperatures computed for each meteorite analyzed during this study.

Figure 8: Average $\Delta^{17} \mathrm{O}$ of $\mathrm{Ca}$-carbonates relative to the average temperature of carbonate precipitation. A general positive trend is observed suggesting that the more altered CMs experienced carbonate precipitation at lower temperature than the least altered CMs.

Figure 9: Average $\Delta^{17} \mathrm{O}$ of Ca-carbonates relative to the Rubin's degree of alteration of the CM chondrites (Rubin et al., 2007). A general positive trend is observed suggesting that the average $\Delta^{17} \mathrm{O}$ could represent a valuable proxy of the degree of alteration. Jbilet Winselwan is classified as a CM 2.0-2.3. 

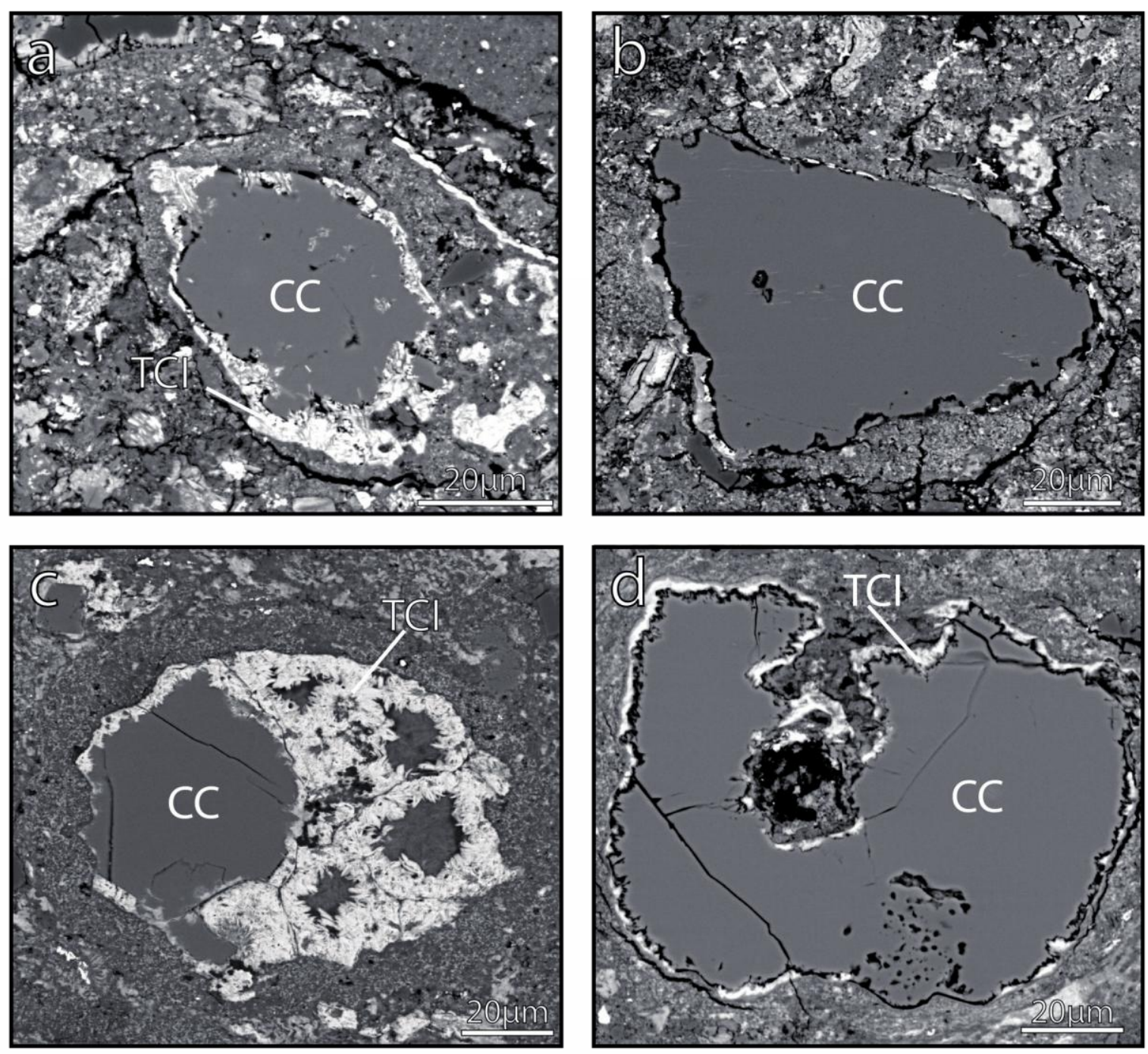

657

658

659

Fig. 1 

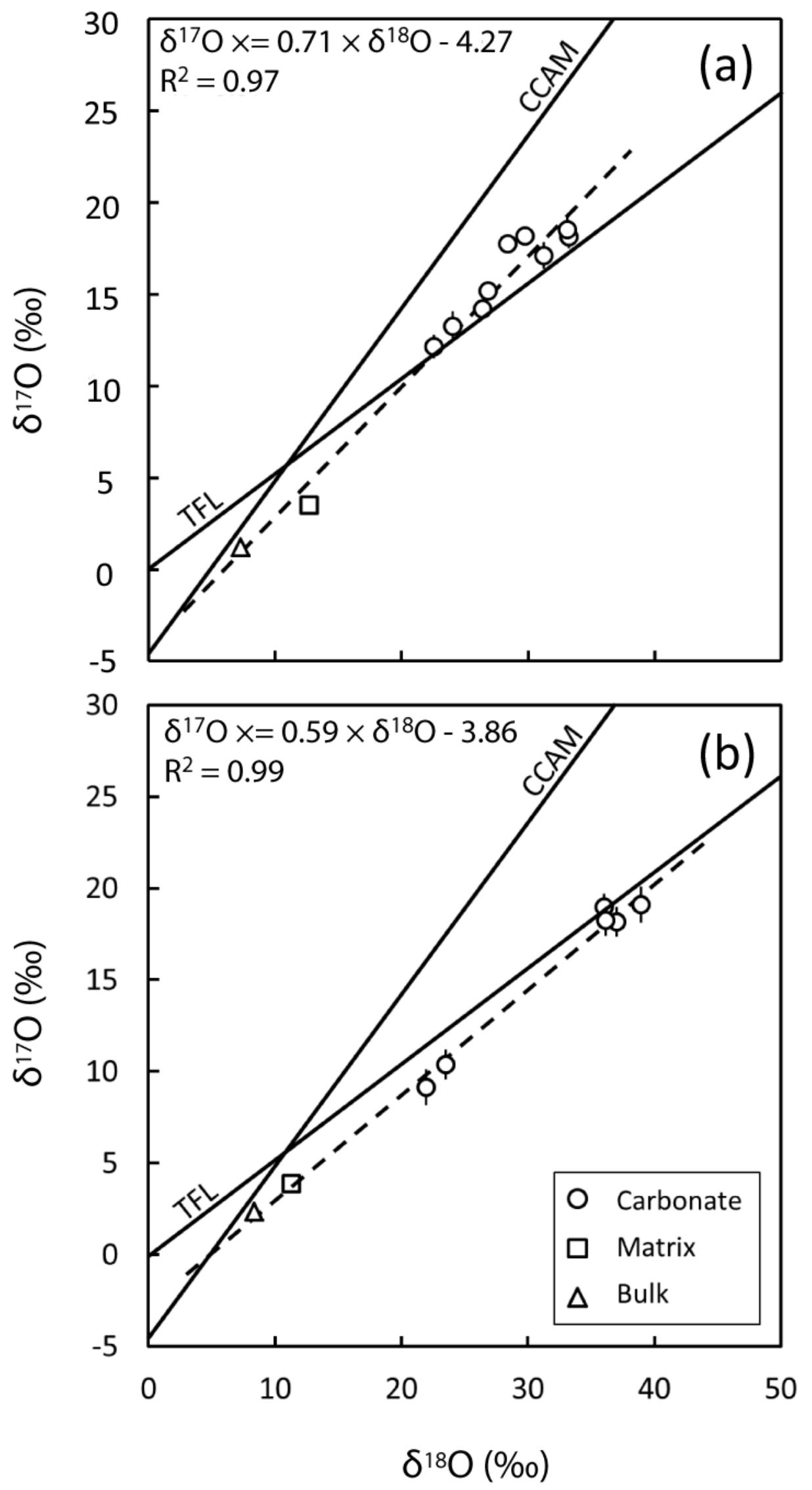

Fig. 2 


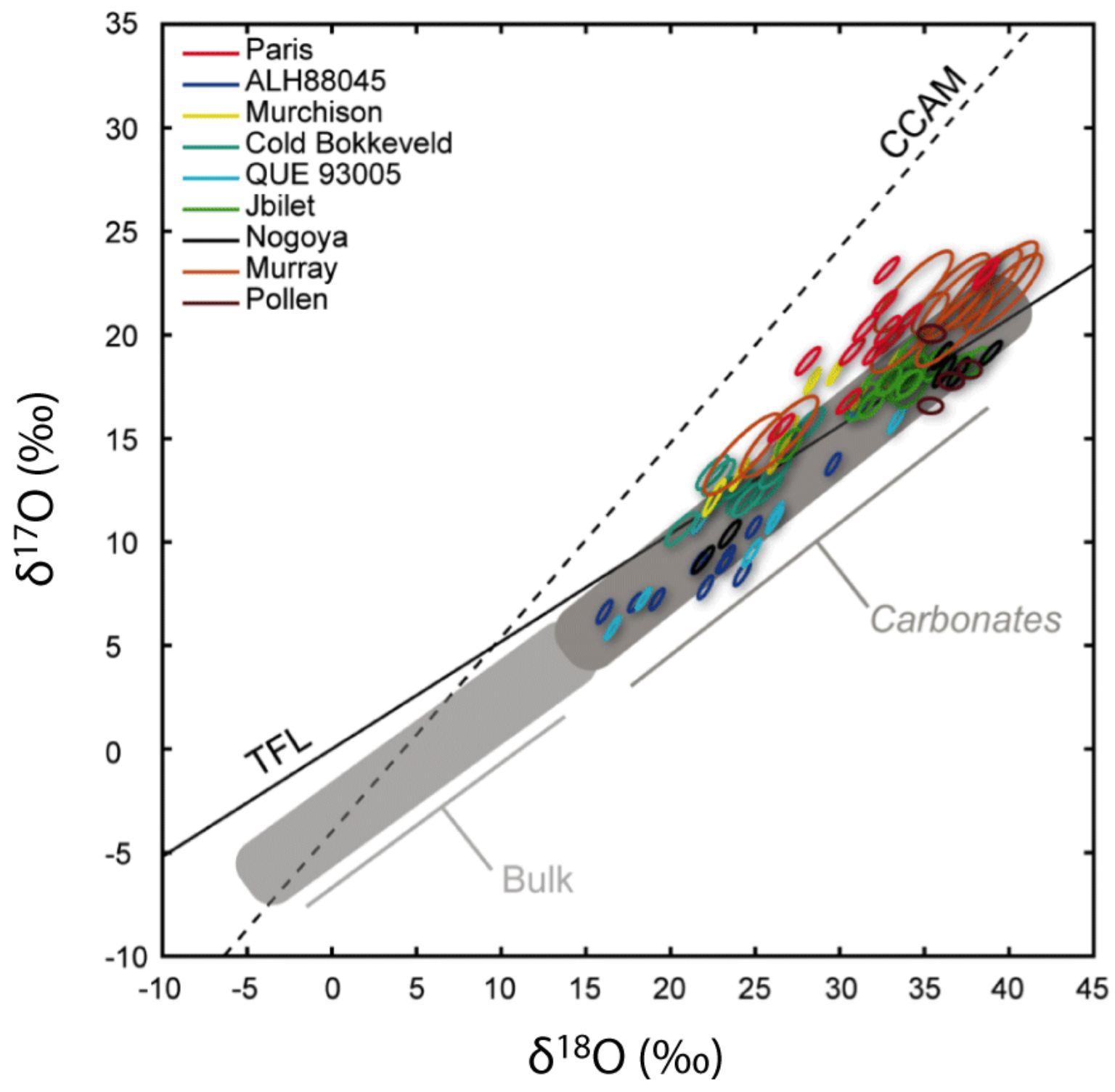

663

Fig. 3

666

667

668

669

670

671

672 

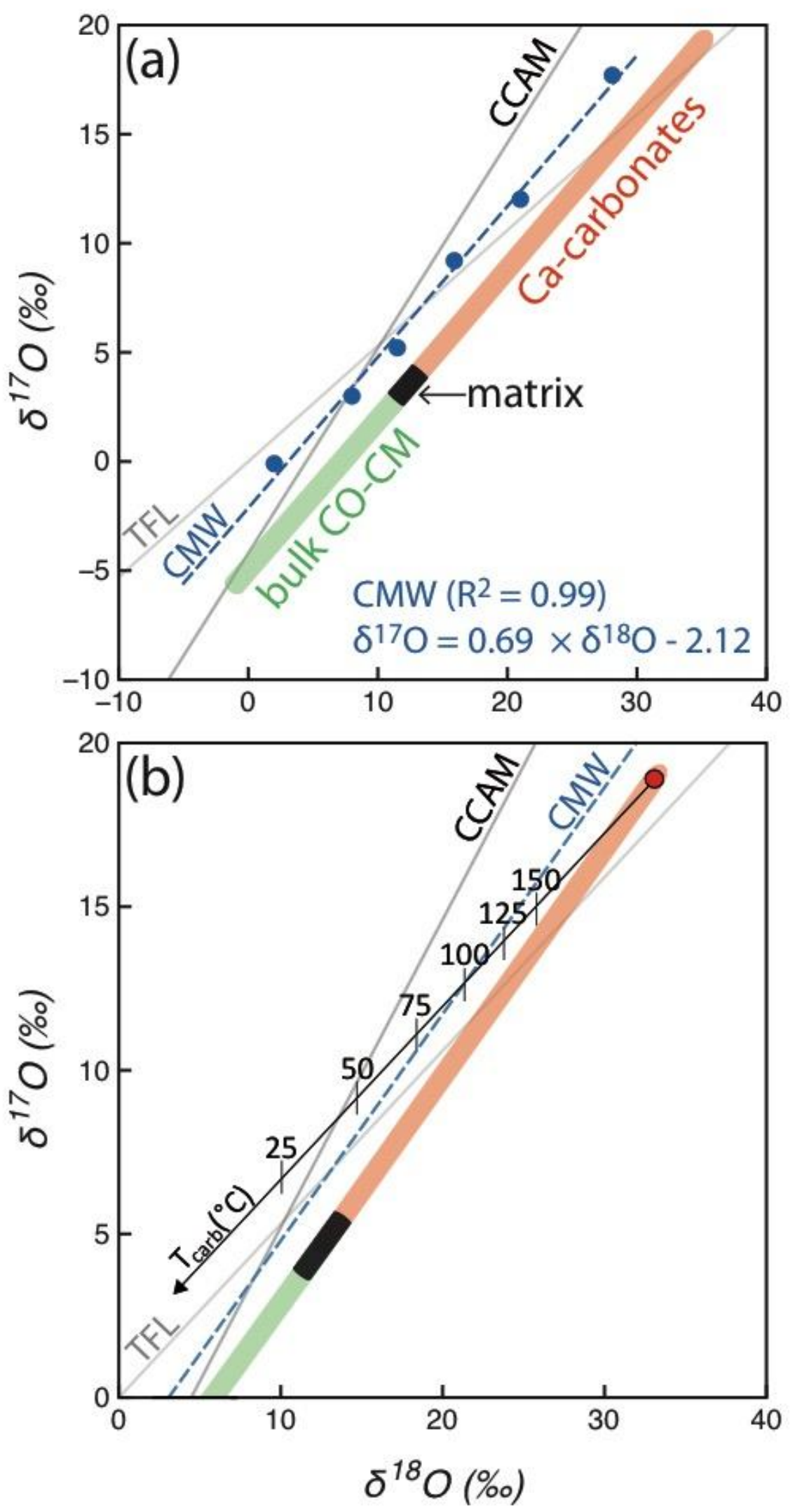

Fig. 4 

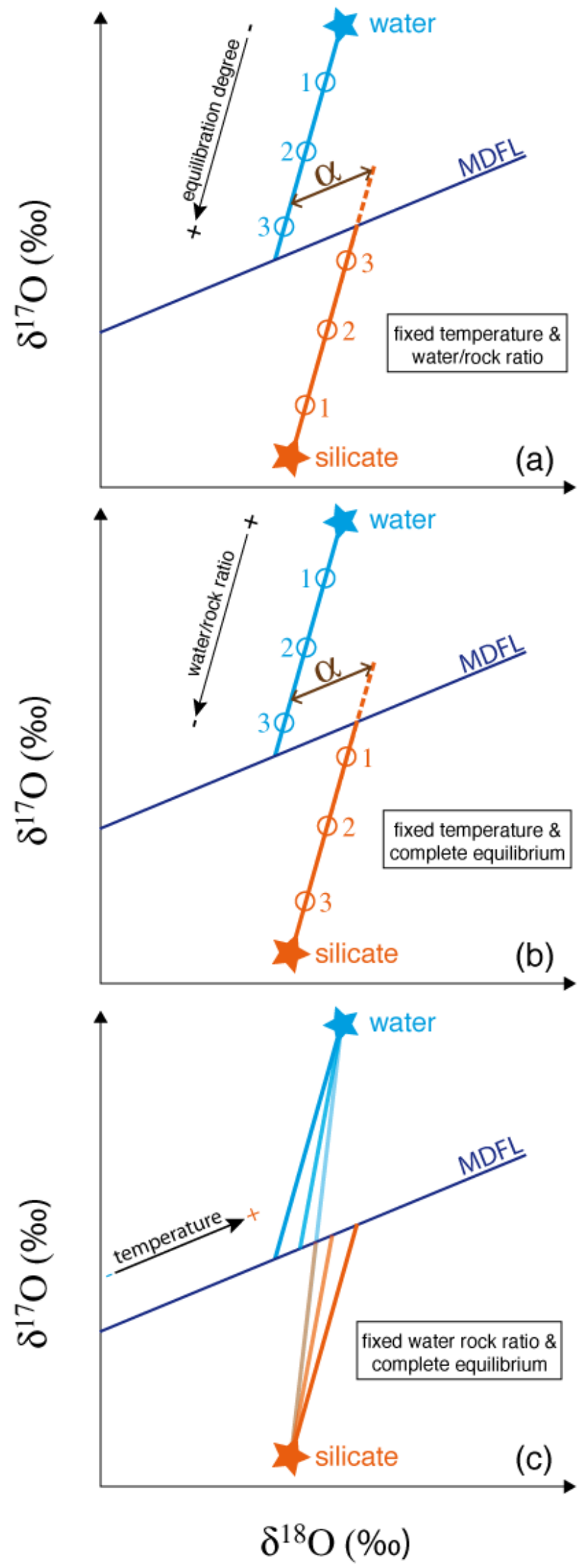

Fig. 5 


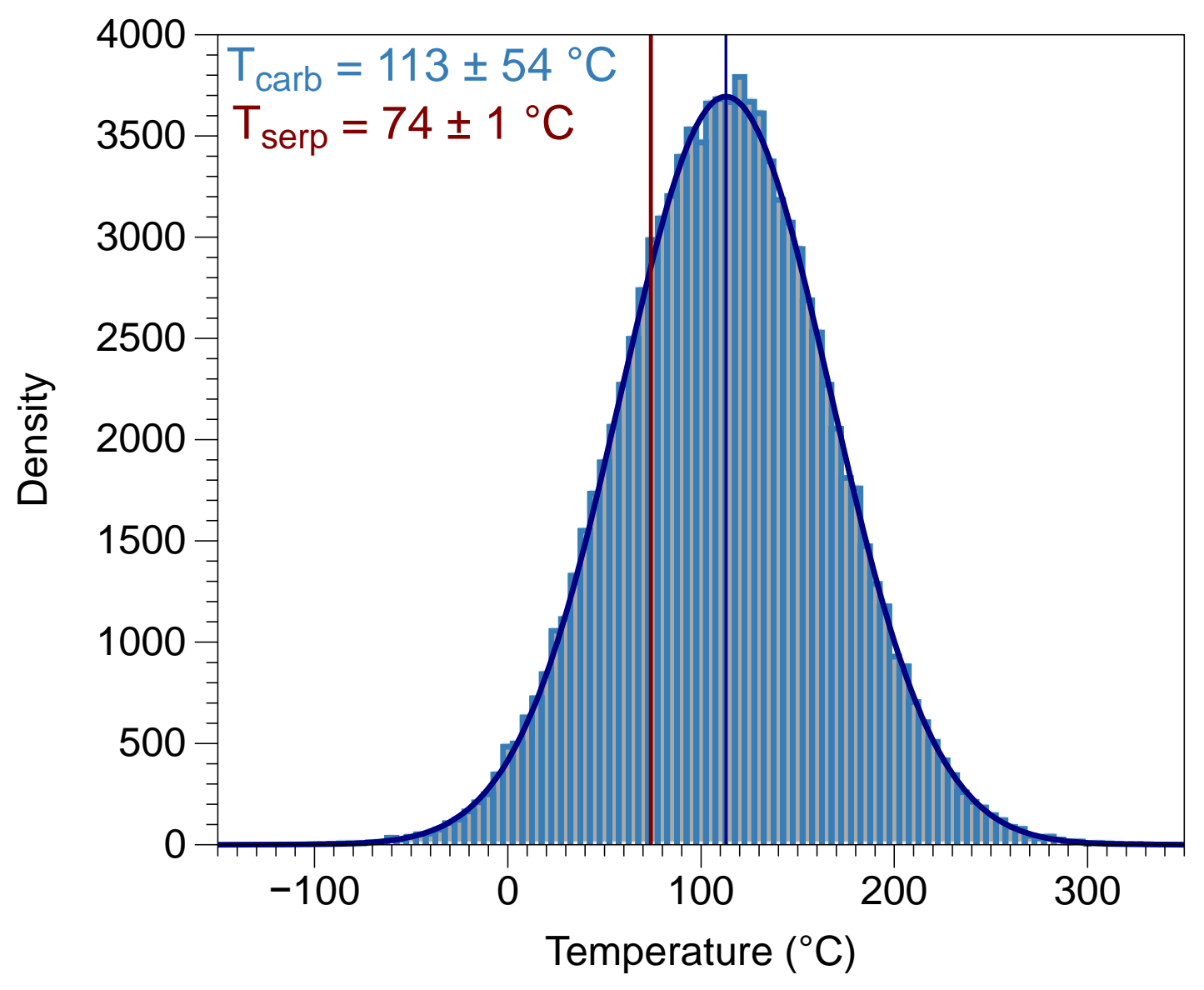

679

680

681

Fig. 6

682 

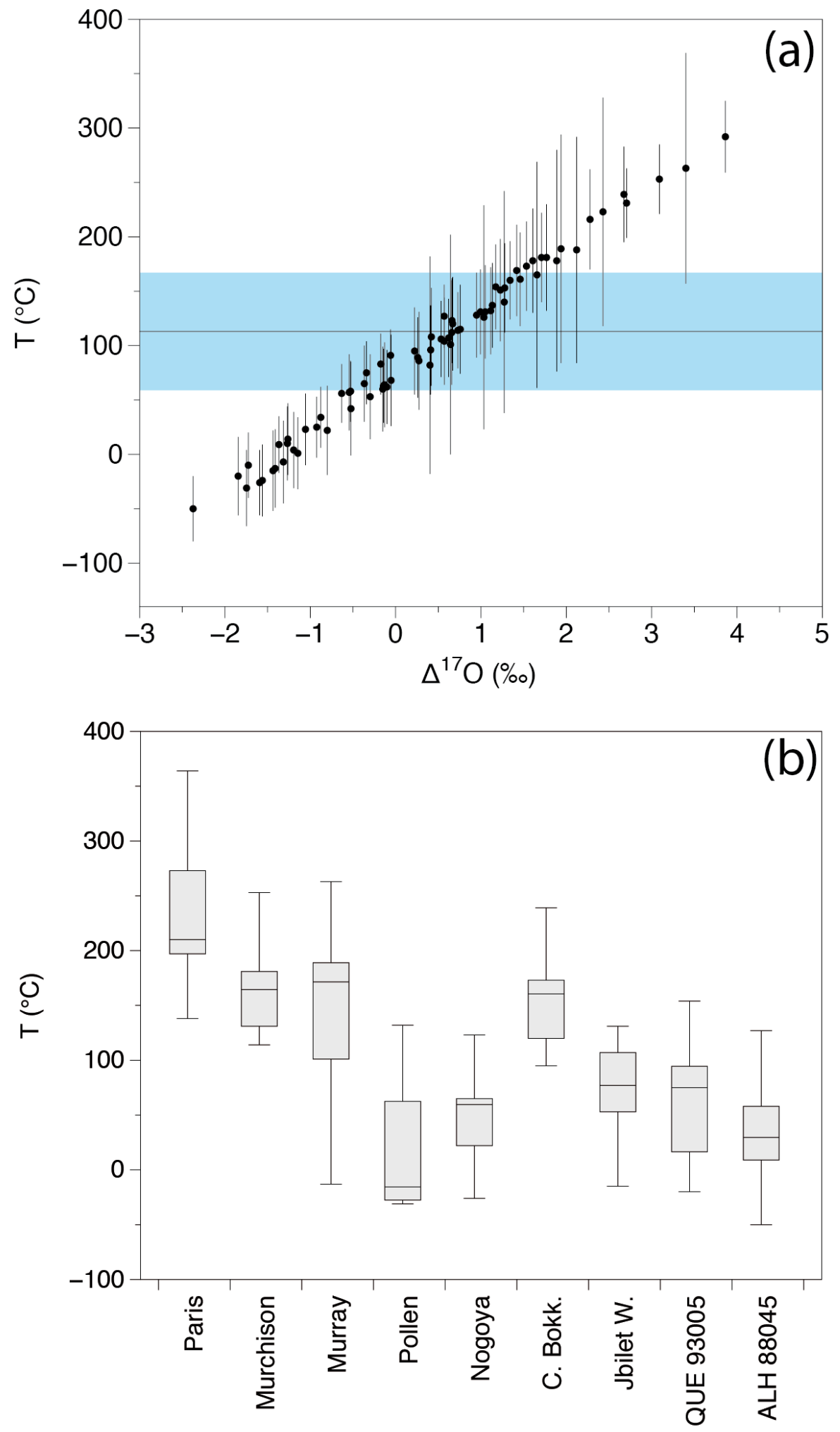

683

684

Fig. 7 


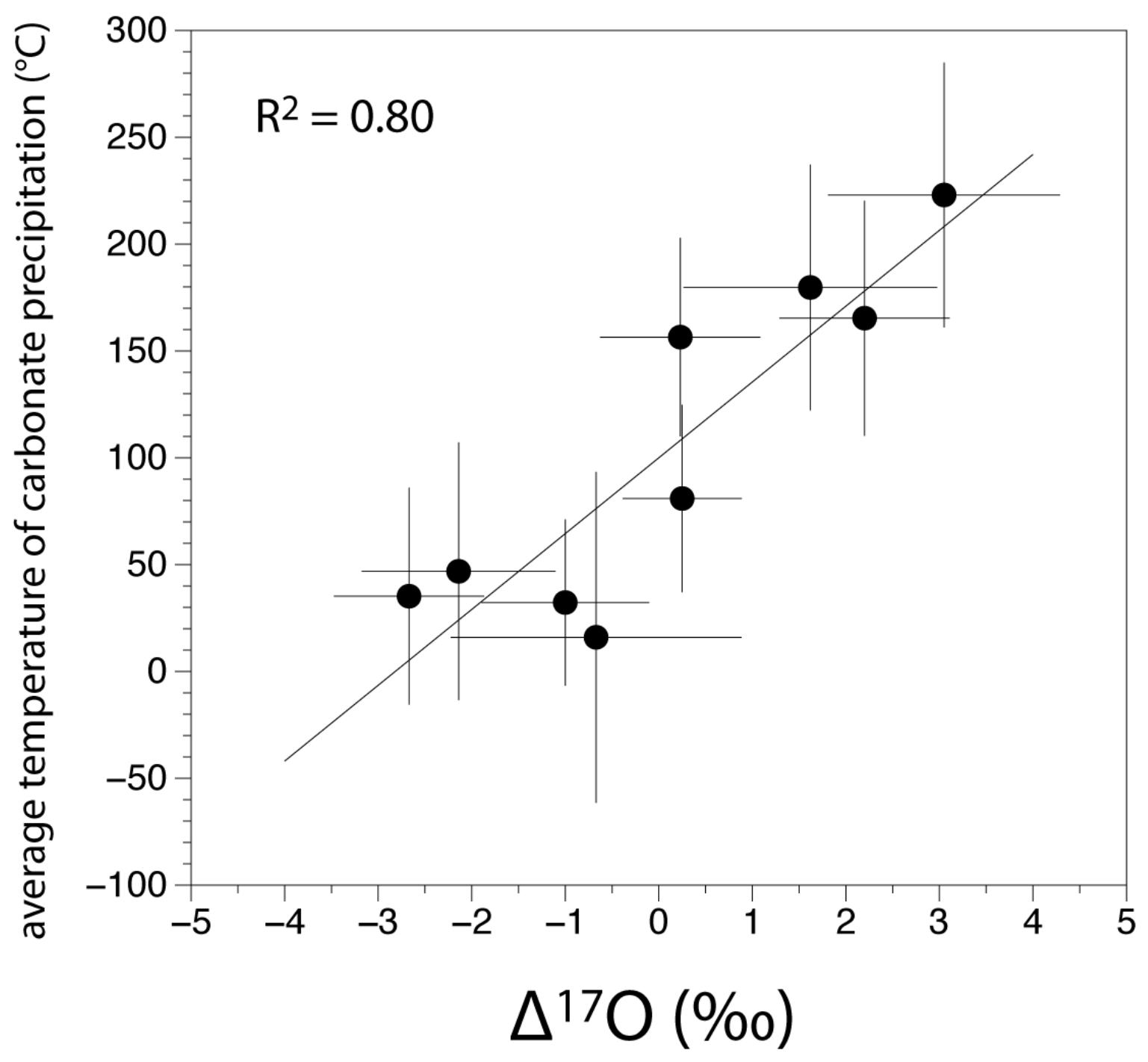

687

688

689

Fig. 8

690 


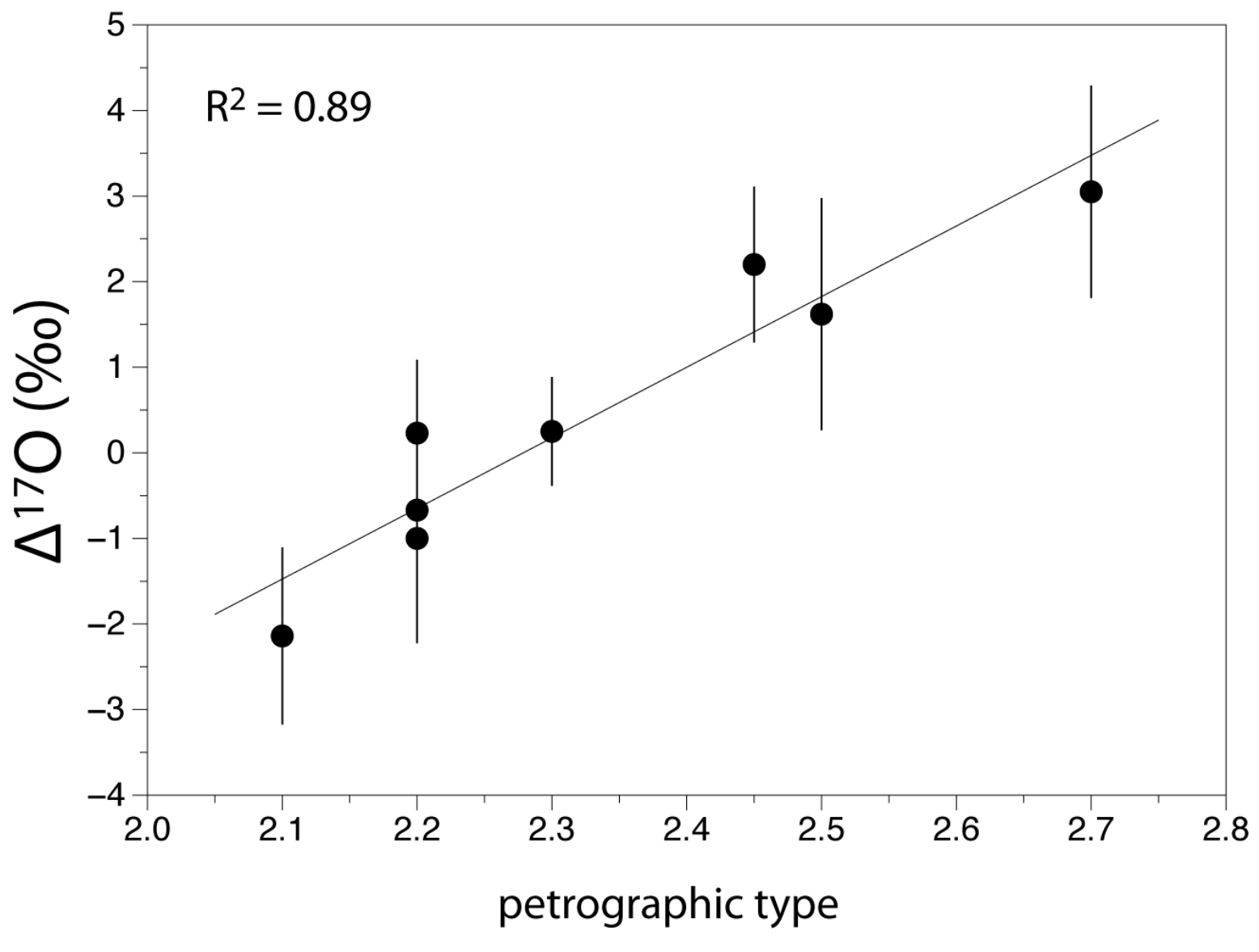

691

692

693

Fig. 9

694

695

696

697

698

699

700

701

702

703 


\begin{tabular}{|c|c|c|c|c|c|c|c|}
\hline chondrite & & $\delta^{18} 0$ & $2 \sigma$ & $\delta^{17} 0$ & $2 \sigma$ & $\Delta^{17} 0$ & $2 \sigma$ \\
\hline \multirow[t]{16}{*}{ Paris (CM 2.7) } & Ca-Carb1a & 30.5 & 0.7 & 16.8 & 0.5 & 0.9 & 0.3 \\
\hline & Ca-Carb1b & 26.5 & 0.8 & 15.5 & 0.6 & 1.7 & 0.4 \\
\hline & Ca-Carb2a & 33.1 & 0.7 & 19.8 & 0.5 & 2.6 & 0.3 \\
\hline & Ca-Carb2b & 32.9 & 0.7 & 19.7 & 0.5 & 2.6 & 0.4 \\
\hline & Ca-Carb2b & 34.1 & 0.7 & 20.8 & 0.6 & 3.1 & 0.4 \\
\hline & Ca-Carb3a & 30.7 & 0.7 & 19.2 & 0.6 & 3.2 & 0.4 \\
\hline & Ca-Carb4a & 32.1 & 0.7 & 19.2 & 0.5 & 2.5 & 0.4 \\
\hline & Ca-Carb4b & 28.1 & 0.7 & 18.7 & 0.6 & 4.1 & 0.4 \\
\hline & Ca-Carb16a & 38.6 & 0.7 & 22.8 & 0.6 & 2.8 & 0.4 \\
\hline & Ca-Carb19a & 32.8 & 0.7 & 20.2 & 0.7 & 3.2 & 0.5 \\
\hline & Ca-Carb20a & 32.8 & 0.7 & 23.1 & 0.5 & 6.1 & 0.4 \\
\hline & Ca-Carb30a & 38.7 & 0.7 & 23.1 & 0.6 & 3.0 & 0.4 \\
\hline & Ca-Carb33a & 31.5 & 0.7 & 20.4 & 0.6 & 4.0 & 0.4 \\
\hline & Ca-Carb36a & 32.6 & 0.7 & 21.5 & 0.6 & 4.5 & 0.4 \\
\hline & average & 32.5 & 0.7 & 20.1 & 0.6 & 3.2 & 0.4 \\
\hline & std. dev. & 3.3 & & 2.2 & & 1.3 & \\
\hline \multirow[t]{7}{*}{ Murchison (CM 2.5) } & Ca-Carb1a & 31.2 & 0.3 & 17.1 & 0.8 & 0.9 & 0.7 \\
\hline & Ca-Carb1b & 33.2 & 0.3 & 18.1 & 0.7 & 0.9 & 0.6 \\
\hline & Ca-Carb1d & 33.1 & 0.3 & 18.5 & 0.8 & 1.3 & 0.7 \\
\hline & Ca-Carb2a & 22.6 & 0.4 & 12.1 & 1.0 & 0.4 & 0.8 \\
\hline & Ca-Carb2b & 24.1 & 0.3 & 13.3 & 0.9 & 0.7 & 0.8 \\
\hline & Ca-Carb2c & 26.4 & 0.4 & 14.2 & 1.0 & 0.5 & 0.8 \\
\hline & Ca-Carb2d & 26.9 & 0.4 & 15.2 & 1.0 & 1.2 & 0.9 \\
\hline
\end{tabular}




\begin{tabular}{|c|c|c|c|c|c|c|c|}
\hline & Ca-Carb3a & 28.4 & 0.3 & 17.8 & 0.7 & 3.0 & 0.6 \\
\hline & Ca-Carb4b & 29.7 & 0.3 & 18.2 & 0.7 & 2.7 & 0.5 \\
\hline & average & 28.4 & 0.3 & 16.1 & 0.8 & 1.3 & 0.7 \\
\hline & std. dev. & 3.8 & & 2.4 & & 0.9 & \\
\hline Murray (CM 2.4-2.5) & Ca-Carb4a & 39.4 & 2.4 & 22.6 & 1.7 & 2.1 & 1.2 \\
\hline & Ca-Carb5a & 39.7 & 2.4 & 22.0 & 1.7 & 1.4 & 1.1 \\
\hline & Ca-Carb10a & 26.4 & 2.4 & 15.1 & 1.8 & 1.3 & 1.2 \\
\hline & Ca-Carb10b & 24.3 & 2.4 & 14.2 & 1.8 & 1.6 & 1.2 \\
\hline & Ca-Carb14a & 38.4 & 2.4 & 22.2 & 1.7 & 2.2 & 1.2 \\
\hline & Ca-Carb16a & 36.5 & 2.4 & 22.0 & 1.7 & 3.0 & 1.2 \\
\hline & Ca-Carb24a & 34.1 & 2.4 & 20.1 & 1.7 & 2.4 & 1.2 \\
\hline & Ca-Carb24b & 34.4 & 2.4 & 22.1 & 1.8 & 4.2 & 1.2 \\
\hline & Ca-Carb33a & 36.8 & 2.4 & 20.4 & 1.7 & 1.3 & 1.2 \\
\hline & Ca-Carb34a & 36.9 & 2.4 & 21.7 & 1.7 & 2.5 & 1.2 \\
\hline & average & 33.5 & 2.4 & 19.7 & 1.7 & 2.3 & 1.2 \\
\hline & std. dev. & 5.2 & & 3.2 & & 1.0 & \\
\hline Pollen (CM 2.4) & Ca-Carb10a & 36.6 & 0.4 & 17.8 & 0.7 & -1.2 & 0.6 \\
\hline & Ca-Carb10b & 37.7 & 0.4 & 18.3 & 0.7 & -1.3 & 0.5 \\
\hline & Ca-Carb16a & 35.4 & 0.4 & 20.0 & 0.8 & 1.6 & 0.7 \\
\hline & Ca-Carb17a & 35.4 & 0.4 & 16.6 & 0.7 & -1.8 & 0.6 \\
\hline & average & 36.3 & 0.4 & 18.2 & 0.7 & -0.7 & 0.6 \\
\hline & std. dev. & 1.1 & & 1.4 & & 1.6 & \\
\hline
\end{tabular}




\begin{tabular}{|c|c|c|c|c|c|c|c|}
\hline \multirow{8}{*}{ Nogoya (CM 2.2) } & Ca-Carb7a & 37.0 & 0.6 & 18.2 & 0.7 & -1.1 & 0.5 \\
\hline & Ca-Carb10a & 36.0 & 0.6 & 19.0 & 0.7 & 0.3 & 0.5 \\
\hline & Ca-Carb11a & 23.5 & 0.6 & 10.4 & 0.7 & -1.8 & 0.5 \\
\hline & Ca-Carb11b & 21.9 & 0.6 & 9.1 & 0.7 & -2.3 & 0.5 \\
\hline & Ca-Carb14a & 36.2 & 0.6 & 18.2 & 0.8 & -0.6 & 0.6 \\
\hline & Ca-Carb15a & 38.9 & 0.7 & 19.1 & 0.5 & -1.1 & 0.3 \\
\hline & average & 31.3 & 0.6 & 15.2 & 0.7 & -1.1 & 0.5 \\
\hline & std. dev. & 8.0 & & 5.0 & & 1.0 & \\
\hline \multirow[t]{12}{*}{ Cold Bokkeveld (2.2) } & Ca-Carb1a & 24.2 & 1.0 & 12.1 & 0.6 & -0.5 & 0.4 \\
\hline & Ca-Carb1b & 23.0 & 1.0 & 12.3 & 0.7 & 0.4 & 0.4 \\
\hline & Ca-Carb1c & 20.6 & 1.0 & 10.6 & 0.7 & -0.1 & 0.5 \\
\hline & Ca-Carb1d & 25.6 & 1.0 & 12.5 & 0.7 & -0.8 & 0.4 \\
\hline & Ca-Carb1e & 24.0 & 0.9 & 12.8 & 0.5 & 0.3 & 0.4 \\
\hline & Ca-Carb2a & 22.5 & 1.0 & 13.4 & 0.8 & 1.7 & 0.5 \\
\hline & Ca-Carb2b & 22.8 & 1.0 & 13.1 & 0.8 & 1.3 & 0.5 \\
\hline & Ca-Carb3a & 24.6 & 1.0 & 12.1 & 0.8 & -0.7 & 0.5 \\
\hline & Ca-Carb3b & 26.2 & 0.9 & 13.4 & 0.7 & -0.2 & 0.5 \\
\hline & Ca-Carb3c & 28.2 & 1.0 & 15.7 & 0.8 & 1.1 & 0.5 \\
\hline & average & 24.2 & 1.0 & 12.8 & 0.7 & 0.3 & 0.5 \\
\hline & std. dev. & 2.1 & & 1.3 & & 0.9 & \\
\hline Jbilet Winselwan (2.0-2.3) & Ca-Carb1a & 27.0 & 0.7 & 14.7 & 0.8 & 0.6 & 0.6 \\
\hline
\end{tabular}




\begin{tabular}{|c|c|c|c|c|c|c|c|}
\hline & Ca-Carb3a & 32.0 & 0.7 & 17.6 & 0.7 & 1.0 & 0.5 \\
\hline & Ca-Carb5a & 35.6 & 0.9 & 18.7 & 0.7 & 0.1 & 0.4 \\
\hline & Ca-Carb8a & 34.3 & 0.9 & 17.3 & 0.8 & -0.5 & 0.5 \\
\hline & Ca-Carb8b & 34.0 & 0.9 & 18.3 & 0.7 & 0.6 & 0.4 \\
\hline & Ca-Carb11a & 33.8 & 0.9 & 18.5 & 0.7 & 1.0 & 0.5 \\
\hline & Ca-Carb14a & 33.2 & 0.9 & 17.9 & 0.7 & 0.7 & 0.4 \\
\hline & Ca-Carb16a & 34.3 & 0.9 & 19.3 & 0.7 & 1.4 & 0.5 \\
\hline & Ca-Carb20a & 34.2 & 0.9 & 18.2 & 0.8 & 0.4 & 0.5 \\
\hline & Ca-Carb20b & 33.7 & 0.9 & 17.5 & 0.7 & 0.0 & 0.5 \\
\hline & Ca-Carb20c & 34.0 & 0.9 & 17.6 & 0.6 & -0.1 & 0.4 \\
\hline & Ca-Carb23a & 31.3 & 0.9 & 16.8 & 0.9 & 0.5 & 0.6 \\
\hline & Ca-Carb32a & 37.2 & 0.7 & 18.5 & 0.6 & -0.8 & 0.4 \\
\hline & Ca-Carb32b & 31.9 & 0.7 & 16.7 & 0.6 & 0.1 & 0.4 \\
\hline & Ca-Carb33a & 35.7 & 0.8 & 18.5 & 0.7 & 0.0 & 0.5 \\
\hline & Ca-Carb34a & 32.9 & 0.7 & 17.8 & 0.6 & 0.7 & 0.4 \\
\hline & Ca-Carb36a & 34.1 & 0.7 & 17.7 & 0.6 & -0.1 & 0.4 \\
\hline & Ca-Carb37a & 38.0 & 0.7 & 18.7 & 0.7 & -1.1 & 0.5 \\
\hline & average & 34.2 & 0.8 & 18.0 & 0.7 & 0.2 & 0.5 \\
\hline & std. dev. & 1.9 & & 0.7 & & 0.7 & \\
\hline QUE93005 (CM2.1) & Ca-Carb1a & 33.4 & 0.4 & 15.9 & 0.7 & -1.4 & 0.6 \\
\hline & Ca-Carb2a & 16.6 & 0.3 & 5.8 & 0.6 & -2.8 & 0.5 \\
\hline & Ca-Carb2b & 18.4 & 0.3 & 7.3 & 0.6 & -2.3 & 0.4 \\
\hline & Ca-Carb2c & 26.2 & 0.3 & 11.3 & 0.7 & -2.3 & 0.6 \\
\hline & Ca-Carb2d & 26.1 & 0.4 & 11.1 & 0.7 & -2.5 & 0.6 \\
\hline & Ca-Carb3a & 21.8 & 0.4 & 11.1 & 0.8 & -0.2 & 0.6 \\
\hline & Ca-Carb4a & 24.8 & 0.4 & 9.5 & 0.7 & -3.4 & 0.6 \\
\hline
\end{tabular}




\begin{tabular}{|c|c|c|c|c|c|c|c|}
\hline & Ca-Carb5a & 31.1 & 0.5 & 16.5 & 0.7 & 0.3 & 0.5 \\
\hline & average & 24.8 & 0.4 & 11.1 & 0.7 & -1.8 & 0.5 \\
\hline & std. dev. & 5.8 & & 3.7 & & 1.3 & \\
\hline \multirow[t]{12}{*}{ ALH88045 (CM 1) } & Ca-Carb1a & 23.3 & 0.4 & 9.2 & 0.7 & -2.9 & 1.2 \\
\hline & Ca-Carb3a & 29.6 & 0.4 & 13.8 & 0.6 & -1.6 & 1.2 \\
\hline & Ca-Carb5a & 19.2 & 0.4 & 7.2 & 0.5 & -2.8 & 1.1 \\
\hline & Ca-Carb5b & 23.2 & 0.5 & 9.0 & 0.5 & -3.1 & 1.1 \\
\hline & Ca-Carb5c & 21.7 & 0.4 & 9.0 & 0.6 & -2.3 & 1.1 \\
\hline & Ca-Carb8a & 17.9 & 0.4 & 7.1 & 0.5 & -2.2 & 1.1 \\
\hline & Ca-Carb8b & 16.1 & 0.4 & 6.6 & 0.6 & -1.7 & 1.2 \\
\hline & Ca-Carb9a & 24.2 & 0.4 & 8.5 & 0.6 & -4.1 & 1.2 \\
\hline & Ca-Carb9b & 24.9 & 0.4 & 10.7 & 0.5 & -2.2 & 1.1 \\
\hline & Ca-Carb9c & 22.1 & 0.4 & 7.8 & 0.6 & -3.7 & 1.2 \\
\hline & average & 22.2 & 0.4 & 8.9 & 0.6 & -2.7 & 1.1 \\
\hline & std. dev. & 3.8 & & 2.1 & & 0.8 & \\
\hline
\end{tabular}

